\title{
Annotations
}

\section{Bone marrow transplantation}

Despite its hazards bone marrow transplantation (BMT) offers the possibility of a lifelong cure for a variety of, otherwise fatal, congenital and acquired disorders of childhood. With increasing understanding of transplantation immunology, and increasing expertise with supportive care, BMT is likely to be more widely used in the next decade. BMT is fairly expensive but it should be borne in mind that transplantation aims at a once and for all lifetime cure, the cost of which must be balanced against the alternative expense of lengthy hospital support of a child with an ultimately fatal illness. Any condition arising in cells derived from totipotential bone marrow stem cells is theoretically susceptible to correction by transplantation of normal stem cells. The table lists current indications and future possibilities for BMT.

\section{Donor selection}

When marrow transplantation is indicated the patient and family are tissue typed to find a compatible donor. While HLA matching is not in itself essential for compatibility, the A and B loci lie next to the all-important $\mathrm{D}$ locus which determines

\section{Table Indications for bone marrow transplantation}

\begin{tabular}{l} 
Of proved value \\
Immune defects \\
Severe combined immune deficiency syndromes \\
Wiskott-Aldrich syndrome ${ }^{9}$ \\
Chédiak-Higashi syndrome ${ }^{10}$ \\
Marrow aplasia 13 \\
Acquired: \\
Idiopathic, postviral, drug-induced, paroxysmal nocturnal haemo- \\
globinuria \\
Congenital: \\
Fanconi type14 \\
Acute leukaemia in remission \\
Acute lymphoblastic leukaemia.7 Common variety, preferably \\
in second remission. Poor risk (B or T cell type), preferably in \\
first remission. \\
Acute myeloblastic leukaemia, ${ }^{8}$ preferably in first remission \\
Osteopetrosis 12 \\
Not yet evaluated11 \\
Ataxia telangectasia \\
Chronic leukaemias and juvenile myeloproliferative syndromes \\
Thalassaemia syndromes and homozygous sickle cell disease \\
Pure red cell aplasia \\
Congenital granulocyte defects: myeloperoxidase deficiency. \\
Congenital enzyme defects: Hurler's syndrome, Gaucher's \\
disease, Tay-Sachs disease, metachromatic leucodystrophy \\
\hline
\end{tabular}

antigens responsible for graft rejection and graftversus-host disease (GVHD). With the exception of rare crossovers, an HLA-identical sibling is therefore also D locus identical. D locus compatibility can be tested by mixed lymphocyte culture. It is occasionally possible to find a compatible parentfor example, after first-cousin marriages; but when grafting for congenital defects the consequences of transplanting bone marrow heterozygous for the patient's condition must be considered. Occasionally it is possible to find an HLA A, B, and D locus identical unrelated donor but very few grafts from such donors have so far been performed.

\section{Supportive care}

A patient with a haematological or an immunological defect has an increased risk of bacterial, viral, or fungal infection. Immunosuppression or antileukaemia treatment also induces granulocytopenia and thrombocytopenia, and transfusion support with platelets, red cells, and occasionally, granulocytes is therefore necessary. There is generally some form of isolation of patients to prevent the risk of exogenous infection. Many leukaemia units use cubicles supplied with filtered sterile air so that patients can be nursed under reverse barrier conditions. An alternative is the plastic isolator tent that can be used in a general ward. ${ }^{1}$ Perhaps of greater importance is the risk of infection from the patient's own bacterial flora. Gut decontamination with nonabsorbable antibiotics and antifungal agents, and topical applications of chlorhexidine to the skin and orifices reduce the chance of infection from resident flora during the period of neutropenia. ${ }^{2}$ Isolation and decontamination procedures are time-consuming and expensive. Unfortunately, data comparing these procedures are lacking.

\section{Transplantation technique}

With the exceptions of bone marrow transplants between identical twins, and patients with severe combined immune deficiency (who are nearly always unable to reject), some form of immunosuppression (usually cyclophosphamide in high doses) is required to permit marrow engraftment. 
In addition, patients with leukaemia require total body irradiation to eradicate residual disease. Bone marrow is aspirated from the donor under general anaesthetic, to obtain about $3 \times 10^{8}$ nucleated bone marrow cells per kilogram recipient weight. Donors tolerate the procedure well and no complications from marrow aspiration have been reported. The bone marrow in heparin is transfused via a blood administration set within a few hours of collection.

\section{Postmarrow transplantation course and problems}

Haematological reconstitution is rapid and most patients achieve normal blood counts within a month of marrow transplantation. Immunological reconstitution is considerably slower and takes between 6 and 12 months before lymphocyte numbers and function have returned to normal. GVHD remains a major problem after transplantation. Prophylactic treatment with methotrexate does not prevent the disease but cyclosporin A may be more effective. ${ }^{3}$ Established GVHD is refractory to most treatment but responds rapidly to high doses of methylprednisolone. Death can occur in the acute stage from overwhelming damage to skin, gut mucosa, and liver, and later from infection and pneumonitis. Early infections after BMT are usually due to bacteria, but opportunistic viral and fungal infections due to impaired cell and humoral immunity can occur up to 12 months after the graft. The new agent acycloguanosine is proving extremely effective in controlling varicella-zoster and herpes virus infections. ${ }^{4}$

\section{Results}

The National Institute of Health transplant registry gives a survival and cure rate of about $60 \%$ in severe combined immune deficiency disease. Success depends on the availability of a compatible sibling donor and adequate support in the months before immunity is fully established. In the absence of a fully compatible donor success with nonmatched marrow or fetal liver transplants is rare, most infants dying from GVHD or incomplete immune reconstitution. ${ }^{5}$

Children grafted for severe aplastic anaemia fare slightly better than adults. A review of patients transplanted in London showed 7 out of 13 surviving transplants in children under age $16^{6} \mathrm{~A}$ major problem with transplantation for marrow aplasia has been failure of engraftment or graft rejection, reaching $50 \%$ in some series. With new regimens using cyclophosphamide and total body or total lymph node irradiation this problem appears to be largely resolved, and improved results are expected. Only $30 \%$ overall survival has been obtained in BMT for Fanconi's aplasia. These children do not reject the graft but suffer early severe toxicity from cyclophosphamide treatment (possibly due to a generalised defect in DNA repair) followed frequently by fatal GVHD. Improvement in these results will depend on devising less toxic conditioning regimens.

Success in leukaemia transplantation is largely related to the patient's condition at the time of grafting. The first results reported in end-stage relapsed leukaemia showed only $10 \%$ long-term survivors. By transplanting earlier in the disease, in remission, most patients survive the graft procedure, but leukaemic relapse may occur up to 2 or 3 years later. Acute lymphoblastic leukaemia (ALL) appears to be less eradicable than acute myeloid leukaemia (AML), and this is reflected in current postgraft survivals of $50-60 \%$ for ALL, compared with $70-80 \%$ for AML. ${ }^{7-8}$

There are reports of successful marrow transplants in a variety of rare disorders-such as WiskottAldrich syndrome, ${ }^{9}$ Chédiak-Higashi disease, ${ }^{10}$ ataxia telangectasia, ${ }^{11}$ and osteopetrosis ${ }^{12}$ but since only a few patients have been transplanted reliable evaluation is not yet possible.

\section{References}

1 Watson J G, Rogers T R, Selwyn S, Smith R G. Evaluation of Vickers-Trexler isolator in children undergoing bone marrow transplantation. Arch Dis Child 1977; 52: 563-8.

2 Storring R A, Jameson E, McElwain T J, Wiltshaw E, Spiers A S D, Gaya H. Oral non-absorbed antibiotics prevent infection in acute non-lymphoblastic leukaemia. Lancet 1977; ii: 837-40.

${ }^{3}$ Powles R L, Clink H M, Spence D, et al. Cyclosporin A to prevent graft-versus-host disease in man after allogeneic bone marrow transplantation. Lancet 1980; i: 327-9.

4 Selby P J, Powles R L, Jameson B, et al. Parenteral acyclovir therapy for herpes virus infections in man. Lancet 1979; ii: 1267-70.

5 Bortin M M, Rimm A A. Severe combined immunodeficiency disease. Characterisation of the disease and results of transplantation. JAMA 1977; 238: 591-600.

6 Barrett A J. Allogeneic bone marrow transplantation for severe aplastic anaemia-the London experience. Clin Lab Haematol 1979; 1 : 95-107.

7 Thomas E D, Sanders J E, Flournoy M, et al. Marrow transplantation for patients with acute lymphoblastic leukemia in remission. Blood $1979 ; 54$ : 468-76.

8 Storb R. Recent results in marrow transplantation for treatment of aplastic anaemia and acute leukaemia in Seattle. In: Thierfelder S, Rodt $H$, Kolb $E$, eds. Immunobiology of bone marrow transplantation. Berlin: Springer Verlag, 1980: 368.

9 Bach F H, Albertini R J, Joo P, Anderson J L, Bortin $M$ M. Bone marrow transplantation in a patient with Wiskott-Aldrich syndrome. Lancet 1968; ii: 1364-6. 
10 Kazmierowski J A, Elin R J, Reynolds H Y, Durbin W A, Wolff S M. Chédiak-Higashi syndrome. Reversal of increased susceptibility to infection by bone marrow transplantation. Blood 1976; 47: 555-9.

11 Hobbs J R. Indications for bone marrow transplantation in inborn errors of metabolism. In the proceedings of the Fourth European Symposium on Bone Marrow Transplantation. Blut 1980; Supplement. In press.

12 Ballett J J, Moutier R, Griscelli C, Toyama K. Lymphoid cell transplantation in experimental and human osteopetrosis. In: Tourain J L, ed. Bone marrow transplantation in Europe. Amsterdam: Excerpta Medica, 1979: 139.

13 Thomas E D, Fefer A, Buckner C D, Storb R. Current status of bone marrow transplantation for aplastic anemia and acute leukemia. Blood 1977; 49: 671-81.

14 Barrett A J, Brigden D, Hobbs J R, et al. Successful bone marrow transplantation for Fanconi's anaemia. Br Med J 1977; i: 420-2.

A J BARRETT Department of Haematology, Westminster Hospital, Dean Ryle Street, London SWIP $2 A P$ 